\title{
Association between Ménière's disease and vestibular migraine
}

\author{
Ilmari Pyykkö $^{\mathrm{a}, *}$, Vinaya Manchaiah ${ }^{\mathrm{b}, \mathrm{c}, \mathrm{d}}$, Markus Färkkilä ${ }^{\mathrm{e}}$, Erna Kentala ${ }^{\mathrm{f}}$, \\ Jing Zou ${ }^{\text {a,f,g }}$ \\ a Department of Otolaryngology, Hearing and Balance Research Unit, University of Tampere, Tampere, Finland \\ ${ }^{\mathrm{b}}$ Department of Speech and Hearing Sciences, Lamar University, Beaumont, Texas, United States \\ ${ }^{\mathrm{c}}$ Department of Speech and Hearing, School of Allied Health Sciences, Manipal University, Manipal, Karnataka, India \\ d Audiology India, Mysore, Karnataka, India \\ ${ }^{\mathrm{e}}$ Helsinki Headache Centre, Helsinki, Finland \\ ${ }^{\mathrm{f}}$ Department of Otorhinolaryngology, University of Helsinki and Helsinki University Hospital, Helsinki, Finland \\ ${ }^{\mathrm{g}}$ Department of Otolaryngology-Head and Neck Surgery, Center for Otolaryngology-Head \& Neck Surgery of Chinese PLA, Changhai \\ Hospital, Second Military Medical University, Shanghai, China
}

A R T I C L E I N F O

\section{Article history:}

Received 11 September 2018

Accepted 3 February 2019

Available online xxx

\section{Keywords:}

Ménière's disease

Vestibular migraine

Migraine

Headache

\begin{abstract}
A B S T R A C T
Objective: The aim of the present study was to evaluate complaints in people with Ménière's disease (MD) with and without migraine and headache to study the association between MD and Vestibular Migraine (VM). We believe this will help us understand if these two disorders represent a disease continuum in that they may share a common aetiology.

Methods: The study used a retrospective design and included data of 911 patients with MD from the Finnish Ménière Federation database. The study participants had a mean age of 60.2 years, mean duration of disease of 12.6 years, and $78.7 \%$ of the participants were females. The questionnaire data comprised of both disease specific and impact related questions. The data were analyzed using the Mann-Whitney U test, the Kruskal Wallis H test, logistic regression analyses, and decision tree analysis. Results: Migraine and headache was reported by 190 subjects $(20.9 \%)$ and 391 subjects (42.9\%) respectively. We found that patients that could be classified as VM in the study (i.e., those with frequent vertigo spells associated with migraine) more often reported complaints of severe MD symptoms, had reduced health-related quality of life, suffered more from anxiety, had more neurological complaints, and experienced a reduced sense of coherence than the non-migraneous patients with MD. However, neither the decision tree analysis nor the logistic regression analysis could reliably discriminate VM from MD patients.

Conclusion: Our study results confirm that MD is frequently associated with headache and migraine. In addition, results also indicate that migraine provokes the severity of MD. We suggest that MD and VM may share similar pathophysiological mechanisms. Hence, the future MD classification systems should include a category referred to as 'MD with migraine' that will include patients with VM.
\end{abstract}

(C) 2019 Elsevier B.V. All rights reserved.

\section{Introduction}

The cardinal symptoms of Ménière's disease (MD) consists of episodic vertigo, fluctuating hearing loss and tinnitus [1]. People

\footnotetext{
* Corresponding author.

URL: http://ilmari.pyykkotuni.fi (I. Pyykkö).
}

with MD also often complain of fullness in the ear, vestibular drop attacks, gait problems, postural instability and nausea. MD is a chronic illness affecting about 190 per 100,000 patients in a US Health-claims database, but in population studies a prevalence of $513 / 100,000$ has been shown [2]. MD originates in the inner ear and can be demonstrated as an enlargement of the endolymphatic space causing endolymphatic hydrops in histological studies [3], 
and recently in MRI [1]. The aetiology of the disease is unknown, and the condition has a chronic course. Having a genetic background, viral sequal and autoimmunity have been suggested as possible aetiologias for MD [1], leading to ailment of the peripheral nerve endings [4]. The diagnosis is based on symptom complex classified by American academy of Otolaryngology Head and Neck Surgery [5] in four categories. In definite MD, the complaints consist of at least two rotatory vertigo attacks lasting for more than $20 \mathrm{~min}$, tinnitus or fullness of the ear, and documented hearing loss in the audiogram. The AAO-HNS definition of MD has been recently modified by the committee members of Barany Society by reducing the categories to "probable MD” and “definite MD" [6].

Migraine is also reported to cause dizziness and vertigo and is overrepresented among patients with MD [7-9]. Migraine Associated Vertigo was jointly classified by the Bárány Society and the International Headache Society, and was consequently re-named as Vestibular Migraine (VM) [9]. VM is classified entirely on the basis of clinical features as reported by the patient. The diagnosis of VM is based on recurrent vestibular symptoms, a history of migraine, a temporal association between vestibular symptoms, and exclusion of other causes of vestibular symptoms. Symptoms that qualify for a diagnosis of VM include various types of vertigo as well as head motioninduced dizziness with nausea. Headache must be of moderate or severe intensity, and the duration of acute episodes is limited to a window of between $5 \mathrm{~min}$ and $72 \mathrm{~h}$ in order to qualify for a diagnosis of VM [9]. Profound abnormalities in the symptomfree interval, such as severe hearing loss and complete unilateral or bilateral vestibular loss are usually indicative of another cause [9]. The concept of brain stem ischemia, which was popular several decades ago, as evidenced by the terms, "vascular headache" [10] and "basilar artery migraine," has largely been supplanted by neurochemical theories that may or may not include a vascular component [11-13]. Phillips et al. [14] indicated that cortical spreading depression causing neuronal and glial depolarization represents the most likely explanation for migraine aura. Brainstem depression solely in the regions of the vestibular nuclei without affecting other brain stem nuclei is implausible [12]. Moreover, family history is often positive for both disorders, suggesting that an inherited syndrome exists which would include a variable expression of migraine and Meniere's features [15]. However, no common genes have been found so far, and the genetics of vestibular migraine are heterogeneous, uncertain, and complicated [16].

Hitherto, there are no objective measurements confirming or rejecting the diagnosis of VM from inner ear disease causing vertigo and dizziness as MD (for review See - Tabet and Saliba [17]). Therefore, researchers have tried to show that migraine is a likely cause of vertigo or dizziness by using two approaches. One approach has been to study randomly selected patients with typical migraine headaches to demonstrate that vertigo and dizziness occur more frequently in migraine patients than in the general population $[18,19]$, while the other method is to study patients with defined vertigo and look for association with migraine [20,21]. Both of these approaches have indicated that there is an overexpression of patients with vertigo among VM; on the other hand, in MD there exists an overrepresentation of patients with migraine. Vestibular symptoms in VM have been reported to occur before the headache in a pattern similar to an aura, during the headache, but also completely independent of the headache [22]. In a review, Tabet and Saliba [17] evaluated published research dealing with MD and migraine to study the association of MD with VM. Unfortunately, there is much overlapping with regard to symptomatology for these two conditions, thus creating diagnostic uncertainty. In fact, some articles excluded the overlap group while others did not consider them. For example, Neff et al. [21] demonstrated that none of the signs, symptoms or investigations could distinguish MD and VM from each other. Almost all of these studies have been carried out without a temporal association of migraine attacks with vertigo attacks, thus creating an uncertainty regarding the coexistence of vertigo and migraine.

Inner ear MRI has been carried out in two studies in order to compare differences between MD and VM. In the study of Nakada et al. [23], both the VM and MD demonstrated a high prevalence of the presence of endolymphatic hydrops in the inner ear. In another study, conducted by Gürkov et al. [24], it was demonstrated that VM had a less frequent prevalence of endolymphatic hydrops than in MD. In VM, transient endolymphatic hydrops has also been described [25]. The challenges in diagnosis of MD and VM has been highlighted by Phillips et al. [14], who has criticized the loosely assessed diagnoses of vertigo attacks with migraine, and thus stated that VM has emerged as a popular diagnosis to fill the void left by the entity known as "vestibular MD" to search for a better explanation. Some authors have even gone as far as suggesting that "vestibular MD" based on AAO-HNS earlier classification [26] is actually undiagnosed VM [27]. It seems that the concept of "vestibular MD" indicates that there exists a subgroup of patients with "possible MD" (as in about $20 \%$ of patients) in which the complete triad of MD [28] takes more than 5-10 years to develop. The symptom-based classifications make the diagnostic work up of individual patients difficult [24,29].

The aim of the present study was to evaluate complaints in people with MD who are presented with and without migraine and headache in order to study the association between MD and VM. In particular, we used the temporal association to evaluate whether the complaints of MD, headache and migraine differ between patients classified as MD. We hypothesized that by examining the differences and similarities in MD and VM, we may understand if these two disorders represent a disease continuum in that they may share a common aetiology.

\section{Method}

\subsection{Study design and participants}

The study used a retrospective design. Permission was obtained from the Finnish Ménière Federation (FMF; Suomen Meniere-liitto) to allow access to the FMF registry data anonymously (i.e., without the personally identifiable information of subjects). The registry data contained detailed data on disease that the FMF had collected from their members when establishing the computer based diagnostic and peer support program during the years 2005-2016 [30-35]. Under Finnish 
law, this kind of study conducted in association with patient association does not require ethical approval. The data was collected from 961 of the 1646 FMF members. From the existing data, information about the diagnosis of migraine was missing in 50 subjects and therefore 911 patients were included in the current study. The mean age of the participants was 60.2 years (range- 80 years, $\mathrm{SD}=12.1$ years). The duration of the disease on average was 12.6 years (range $0.5-50$ years, $\mathrm{SD}=11.2$ years). Participants included 717 females (i.e., $78.7 \%$ ) and 194 males (i.e., 21.3\%) respecting the gender distribution of FMF and prevalence of MD in Finland [2].

\subsection{Data collection}

All of the questionnaires were administered in Finnish. The questionnaires were comprised of both disease specific and impact related questions including: (1) an oto-neurology questionnaire [36-38]; (2) EuroQolEQ-5D-3L general-health related quality of life measure [39]; (3) sense of coherence [40]; and (4) specific questions on anxiety or nervousness and vitality taken from the general health related quality of life instrument 15D [41].

Attitude toward illness is one of the key elements in determining the individual's ability to cope with the illness [42]. Antonovsky [40] developed the concept of the sense of coherence to define salutogenesis i.e., the means of helping oneself through the difficulties of life. The sense of coherence consists of three main components, which include: (a) cognitive component - the ability to understand what is happening; (b) manageability component - the manageability of life situations in social networks; and (c) the meaningfulness component - the ability to a find meaning in life. The sense of coherence has been shown to be a critical variable in predicting treatment outcomes, especially in terms of psychosocial adaptation and subjective adaptability to a medical condition. The sense of coherence score is stable when it is high, while a low sense of coherence is more likely to improve on acquiring more life experience. In MD, Ketola et al. [43] showed that coping with MD is better in those having a higher sense of coherence scores indicating that a higher sense of coherence may reflect positive optimism, which may indicate acceptance and subsequently better management of restrictions caused by MD.

The oto-neurology questionnaire consisted of 102 items and covered all elements of the disease including onset of the complaints, characterization of vertigo, balance problems, mobility related problems, hearing loss, tinnitus and hyperacusis, and associated complaint. In the diseasespecific impact evaluation, the patients were asked to rate the impact caused by MD by different complaints in a fourpoint Likert scale. The diagnosis of migraine was based on previous medical evaluations mostly carried out by neurologists. We also used a question to confirm the diagnosis of migraine: Do you have migraine which has been diagnosed by a physician? Headache was queered with 4 questions. Questions about migraine included: How often does the headache occur? and How long does the headache last? Possible association of headache with vertigo spells were explored in the question: Do you have headaches during vertigo attacks? Based on the responses to these questions, participants were classified into five groups. The questionnaire also included questions about neurological symptoms, history of general health, family history, metabolic and cardiovascular diseases, possible use of ototoxic or vestibulotoxic drugs, history of possible inner ear injuries and head and neck injuries, ear surgeries and other diseases that may influence balance. Finally, the questionnaire contained questions related to symptoms and their effects on life in addition to questions related to personal characteristics.

\subsection{Data analysis}

The data were analyzed using various non-parametric and parametric statistics. The Mann-Whitney $\mathrm{U}$ test and the Kruskal Wallis $\mathrm{H}$ test were used to investigate the association between demographic details as well as complaints about the disease. In the results, the Chi square value instead of ranks are provided to illuminate the strength of the association. The between group comparison was made with the Mann-Whitney test. The dependencies between these factors were examined using logistic regression analysis. For continuous variables we used analysis of variance (ANOVA) in statistical comparison. The association of specific complaints were analyzed with logistic regression analyses. In classification of the variables between complaints of migraneous patients with frequent vertigo and those without migraine associated vertigo used decision tree analysis. A $p$-value of 0.05 was used for interpretation of statistical significance.

\section{Results}

\subsection{Characteristic of pain in the head and association with vertigo}

The association of vertigo attacks with migraine or headache was scaled as no, rarely, moderately often, frequently, and very frequently (See Table 1). No headache associated with vertigo was reported by 518 subjects (56.9\%), rarely by 194 subjects (21.3\%), moderately often by 126 subjects (13.8\%), frequently by 56 subjects $(6.1 \%)$, and very frequently by 17 subjects $(1.9 \%)$. As the association of vertigo with migraine is one of the key criteria in establishing the diagnosis of VM, we analyzed the occurrence of vertigo with headache and migraine by dividing the association into two groups: (a) those with no association or rare association; and (b) those with vertigo occurring with migraine moderately often, frequently, and very frequently. The patients with migraine did not differ from those with headache by having more frequent association with vertigo (Mann-Whitney test, $\mathrm{Z}=1.189, p=0.23$ ).

Pain in the head (headache or migraine) occurred less than annually in 37 subjects (4.1\%), less than once in a month by 207 subjects $(22.7 \%)$, occurring monthly by 190 subjects (20.7\%), occurring weekly by 113 subjects (12.5\%), and daily by 34 subjects $(3.7 \%)$. The pain lasted less than $2 \mathrm{~h}$ by 260 subjects (28.5\%), lasted more than $2 \mathrm{~h}$ but less than $24 \mathrm{~h}$ by 292 subjects (32.1\%), and longer than $24 \mathrm{~h}$ or constant pain by 
Table 1

Association of headache with vertigo spells (Note: Individuals reporting rarely having vertigo with headache is classified as not being associated with vertigo).

\begin{tabular}{|c|c|c|c|c|c|c|}
\hline Association rating & $\begin{array}{l}\text { No headache } \\
(\mathrm{n}=330)\end{array}$ & $\begin{array}{l}\text { Headache not assoc. } \\
\text { vertigo }(n=267)\end{array}$ & $\begin{array}{l}\text { Headache with } \\
\text { vertigo }(n=124)\end{array}$ & $\begin{array}{l}\text { Migraine not ass. } \\
\text { vertigo }(\mathrm{n}=115)\end{array}$ & $\begin{array}{l}\text { Migraine with } \\
\text { vertigo }(n=75)\end{array}$ & All $(\%)$ \\
\hline No vertigo with headache & 330 & 132 & 0 & 56 & 0 & $518(56.9 \%)$ \\
\hline Rarely vertigo with headache & 0 & 135 & 0 & 59 & 0 & $194(21.3 \%)$ \\
\hline Moderately often vertigo with headache & 0 & 0 & 83 & 0 & 43 & $126(13.8 \%)$ \\
\hline Frequently vertigo with headache & 0 & 0 & 31 & 0 & 25 & $56(6.1 \%)$ \\
\hline Very frequently vertigo with headache & 0 & 0 & 10 & 0 & 7 & $17(1.9 \%)$ \\
\hline Total & $330(36.22 \%)$ & $267(29.3 \%)$ & $124(13.61 \%)$ & $115(12.62 \%)$ & $75(8.23 \%)$ & $911(100 \%)$ \\
\hline
\end{tabular}

29 subjects $(3.2 \%)$. Migraine and headache were reported by 190 subjects (20.9\%) and 391 subjects (42.9\%) respectively. No pain was reported by 330 subjects $(36.2 \%)$. There was no difference between the migraine patients and headache patients in the frequency of the pain attacks (Mann-Whitney test, $\mathrm{Z}=1.189=3, p=0.235$ ), but patients with migraine without associated vertigo had longer duration than the patients with headache (Mann-Whitney test, $\mathrm{Z}=3.13, p=0.001$ ).

\subsection{Association of headache or migraine with vertigo and balance}

We analyzed the characteristics of vertigo attacks and complaints related to postural instability using the KruskalWallis test (Figs. 1 and 2). The study subjects were divided into 5 groups based on headache and migraine shown in Table 1. The Kruskal-Wallis test showed a statistically significant difference a
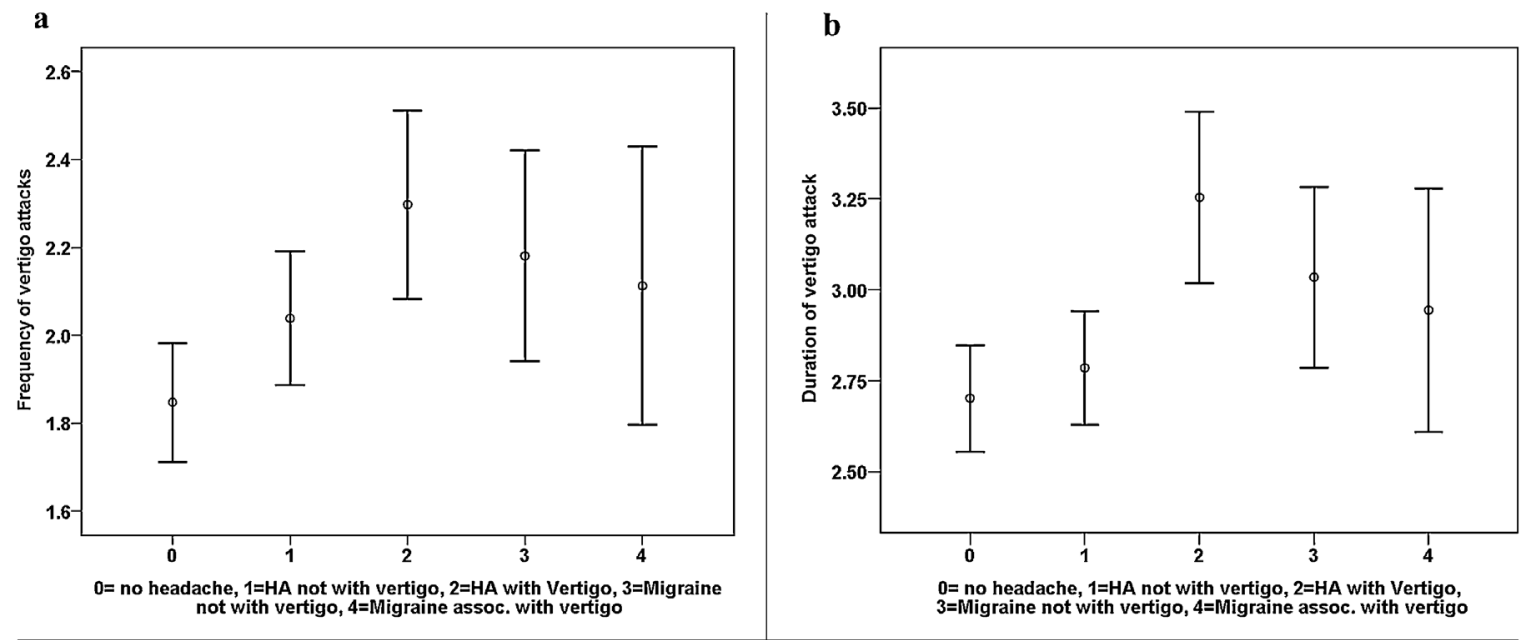

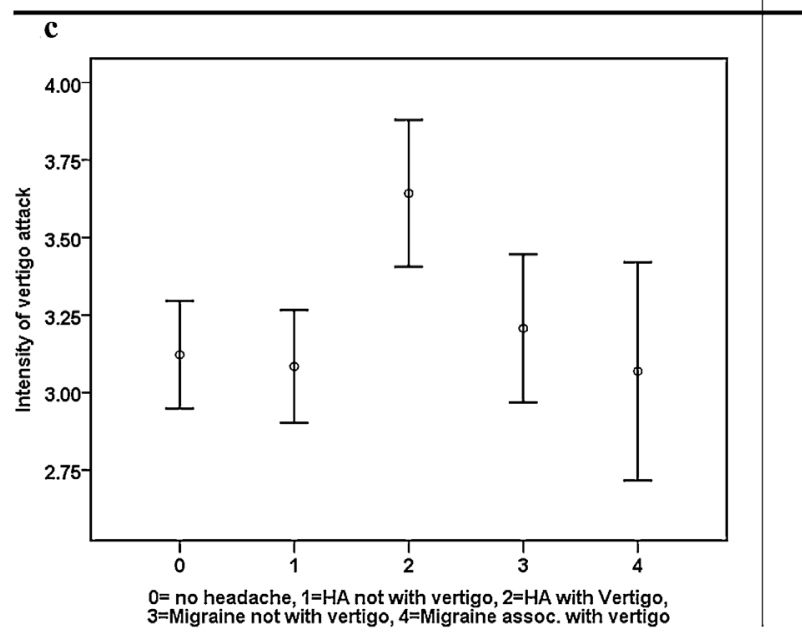

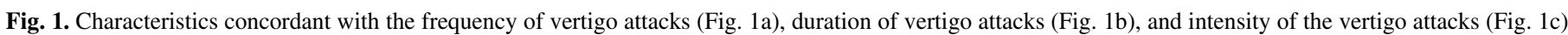

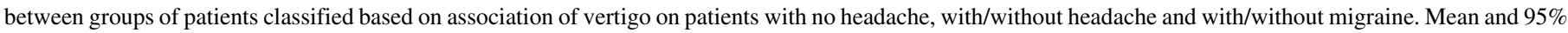
confidence interval (CI) are shown. The complaints are rated in a 5-point scale from non to very frequent, very long, or very intense. 
between the frequency of vertigo attacks (Chi square $=14.849$, $p=0.005$ ) (Fig. 1a), duration of vertigo attacks (Chi square $=$ 18.547, $p=0.001$ ) (Fig. 1b), intensity of vertigo attacks (Chi square $=15.156, p=0.004$ ) (Fig. 1c), unsteadiness between the attack (Chi square $=40.773, p<0.001)$ (Fig. 2a), and mobility outside of the attacks (Chi square $=30.691, p<0.001)$ (Fig. 2b). In comparison of migrenous patients with or without frequent association with vertigo, only mobility outside of vertigo attack tended to be statistically significant (Mann-Whitney test, $\mathrm{Z}=-2.44, p=0.015$ ).

\subsection{Association of headache and migraine with neurological complaints}

We analyzed possible neurological complaints between the no-headache and migraine group (Fig. 3). In all variables selected as blurring of vision or double vision $($ Chi square $=$ $30.599, p<0.001$ ) (Fig. 3a), weakness of voice, stuttering or blurring of speech (Chi square $=48.481, p<0.001$ ) (Fig. 3b), difficulties in swallowing (Chi square $=38.556$, $p<0.001$ ) (Fig. 3c), and tingling in face or disturbance of sensitivity (Chi square $=59.346, p<0.001$ ) (Fig. 3d) were factors found to have statistically significant associations with different patient groups. However, there were no differences between headache and migraine groups found in the secondary analysis.

\subsection{Quality of life}

In the individual components of EuroQolEQ-5D-3L, all variables except the mood variable differed significantly among the groups (Fig. 4). The outcome scores of EQ-5D-3L instruments differed significantly between the no-headache, headache and migraine groups $(\mathrm{F}=16.01, p<0.001)$ (Fig. 4a) and this difference was also observed in the EuroQol VAS instrument $(\mathrm{F}=9.26, p<0.001)$ (Fig. 4b).

\subsection{Sense of coherence, anxiety and fatigue}

We evaluated the association of personal trait measured using the sense of coherence scale in patients with no headache, headache and migraine. The patients with migraine and frequent vertigo had the lowest scores in the sense of coherence instrument, and a statistically significant difference was observed among the groups $(\mathrm{F}=9.34, p<0.001)$ (Fig. 5a). The best scores were among patients without headache and the worst scores among patients with migraine associated vertigo (Fig. 5a).The outcome of replies on anxiety indicated some differences between groups (Chi square $=35.4, p<0.001$ ) (Fig. 5b). Patients with vertigo associated with migraine attacks suffered from greater anxiety than non-headache patients $(p<0.001)$ or patients with headache not associated with vertigo $(p=0.007)$. The outcome of replies on fatigue indicated in MD with migraine attacks suffered from fatigue (Chi square $=55.1, p<0.001)$ (Fig. 5c). In pairwise comparison, the patients with migraine and headache associated with vertigo experienced greater fatigue than non-headache patients ( $p$ $<0.001)$ or patients with headache not associated with vertigo $(p=0.03)$.

\subsection{Modelling migraine associated vertigo}

We classified patients with frequent association of vertigo with migraine in a decision tree analysis to evaluate what characteristics in MD could be related to VM. In the model, only a few factors were significant, and the most important was "paresthesia of the face (Chi square $=21.251, p<0.001)$. The next node "syncope during attack" was also significant (Chi square $=9.265, p=0.007$ ), and was more severe in migrainous vertigo patients. The parallel node "feeling of drunkenness was more common in migrainous vertigo patients (Chi square $=$ $11.167, p=0.001$ ). Finally, "Tumarkin attacks leading to slips or falls" tended to be more common in migraneous patients (Chi a

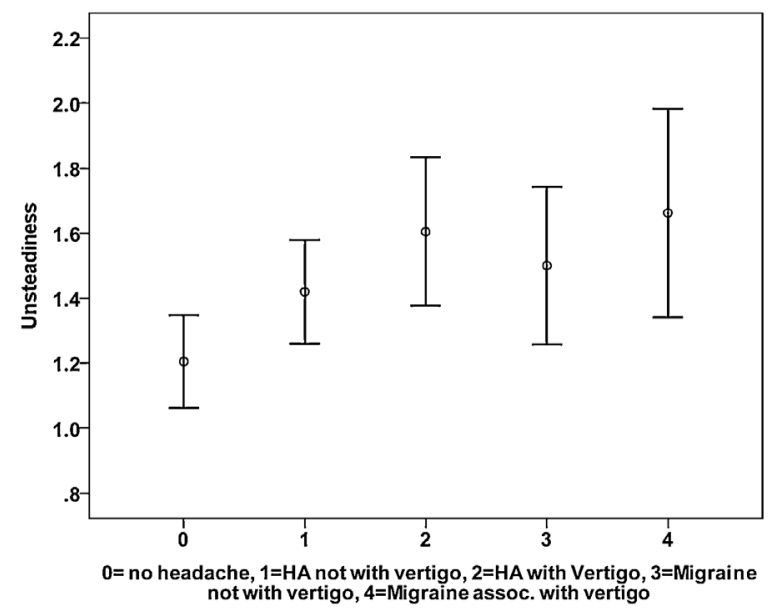

b

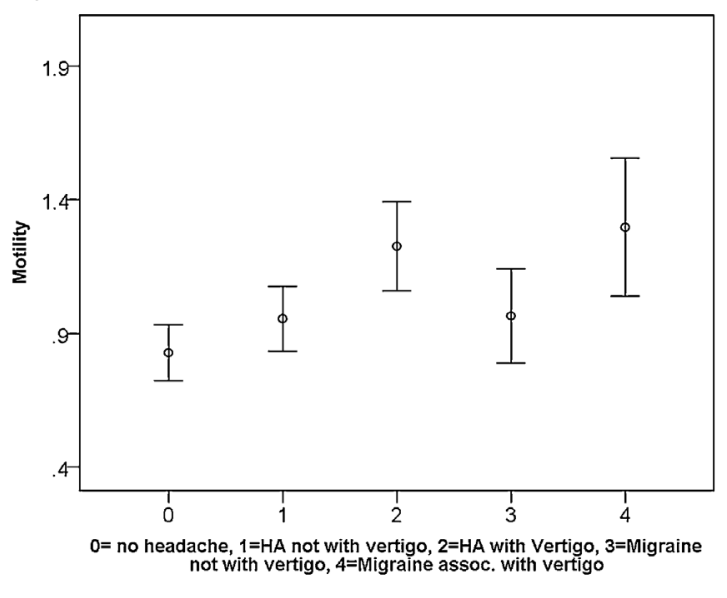

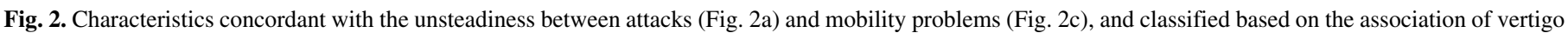

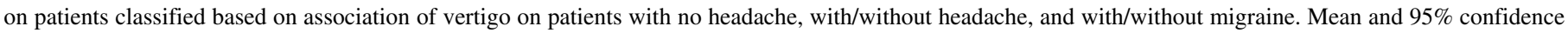
interval (CI) are shown. The complaints are rated in a 5-point scale from none to very intense. 
a

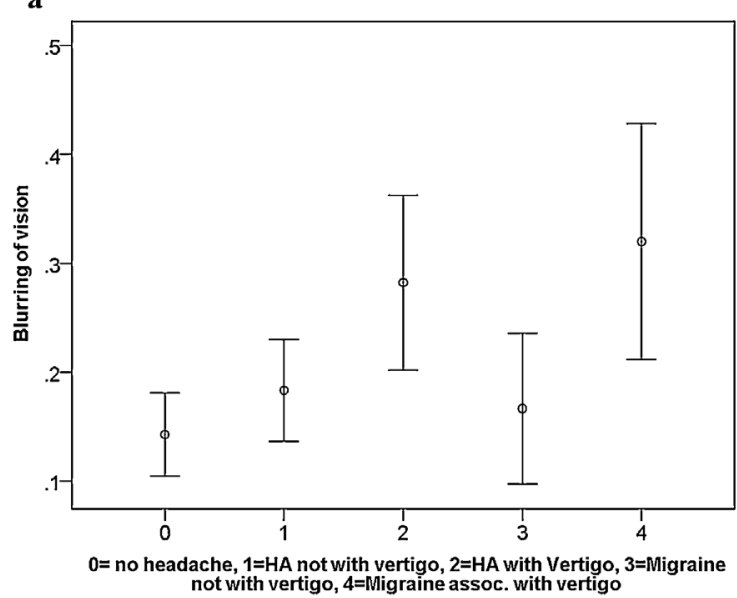

$\overline{\mathbf{c}}$

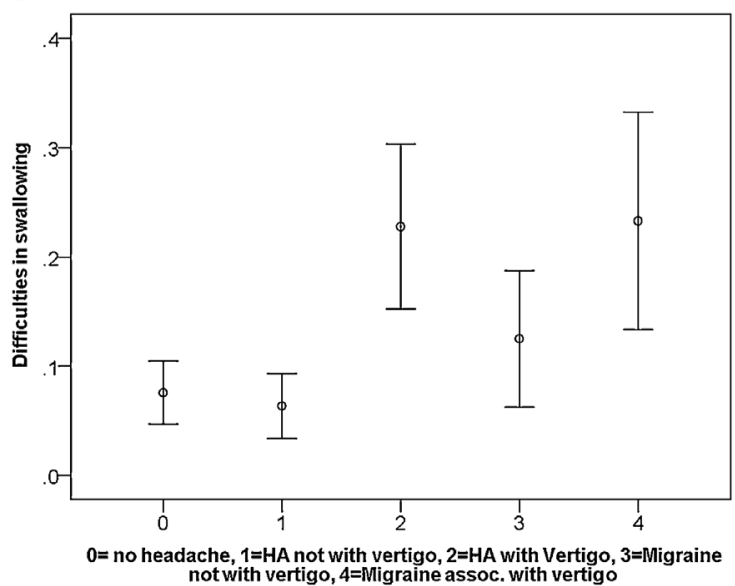

b

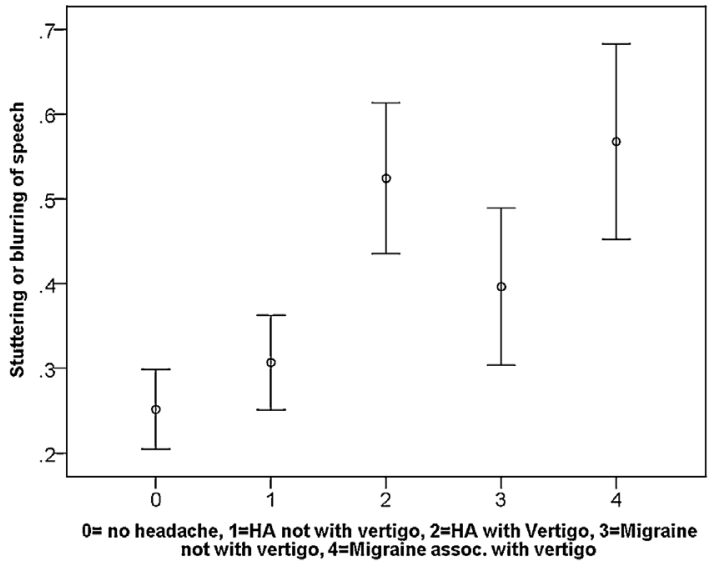

not with vertigo, $4=$ Migraine assoc. with vertigo

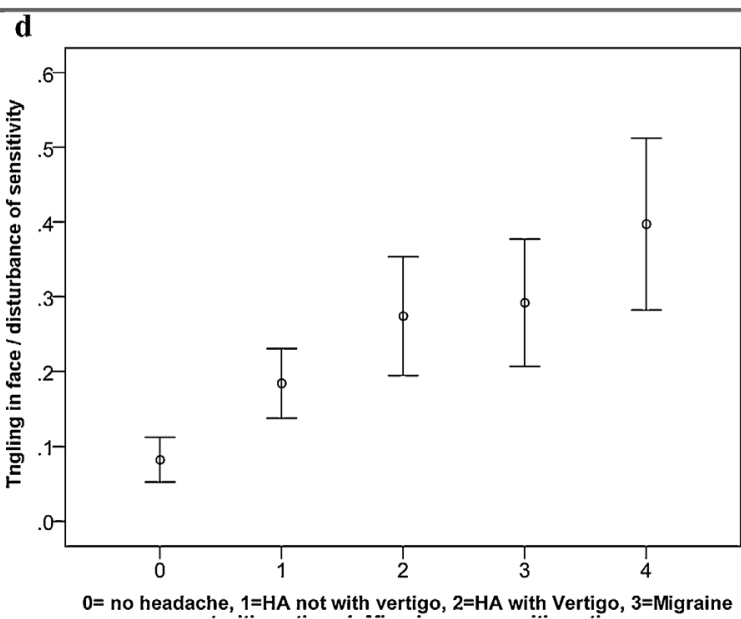

Fig. 3. Association of headache and migraine in patients with MD with neurological complaints regarding MD without headache ( $\mathrm{n}=330$ ), with headache not associated with vertigo attacks $(n=2267)$, with headache associated with vertigo attacks $(n=124)$, with migraine not associated with vertigo attacks $(n=115)$, and with migraine associated with vertigo attacks $(n=75)$. The frequency distribution of the blurring of vision or double vision (Fig. 3a), stuttering or blurring of speech (Fig. 3b), difficulties in swallowing (Fig. 3c), and tingling in the face or disturbance of sensitivity (Fig. 3d) are depicted. Mean and 95\% confidence interval are shown. The occurrence of complaints are rated from none to the present one.

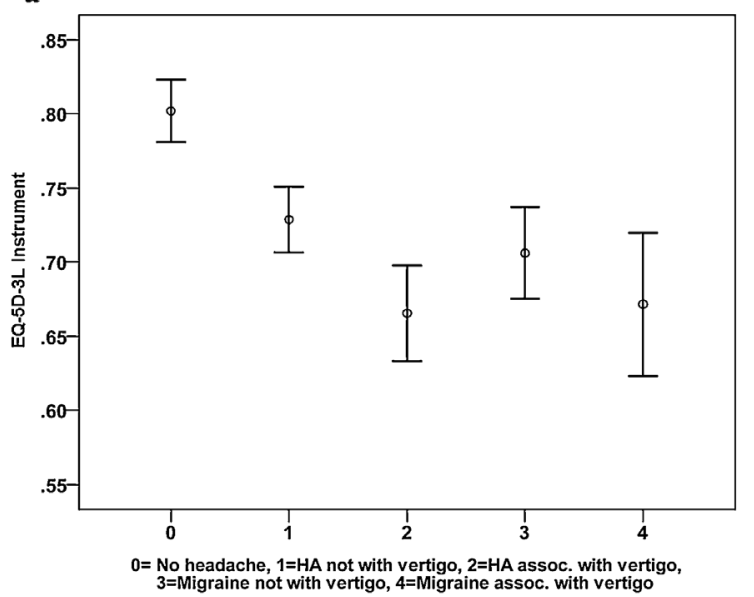

b

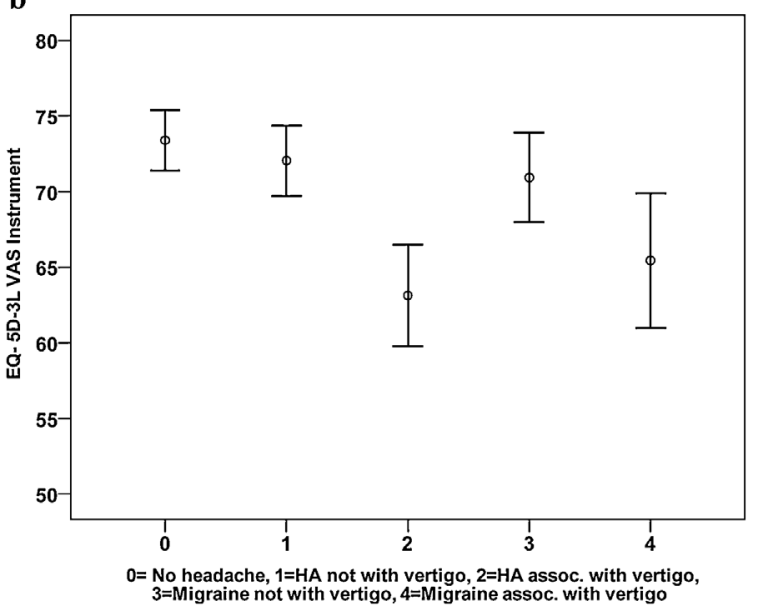

Fig. 4. Quality of life among patients with Meniere's disease classified based on vertigo associated headache. EQ-5D-3L instrument (Fig. 4a) and EQ-5D-3L VAS instrument (Fig. 4b) are classified based on the association of vertigo on patients with no headache, with/without headache, and with/without migraine. Mean and 95\% confidence interval are shown.

Please cite this article in press as: Pyykkö I, et al. Association between Ménière's disease and vestibular migraine. Auris Nasus Larynx (2019), https://doi.org/10.1016/j.anl.2019.02.002 


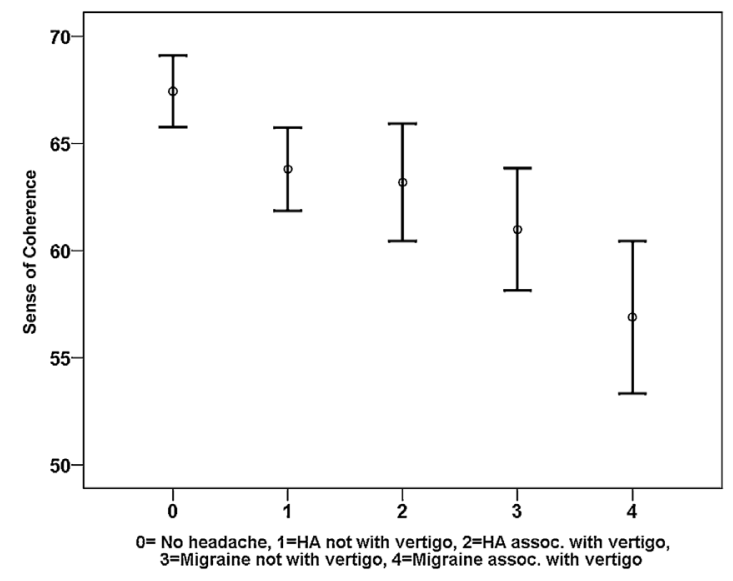

b

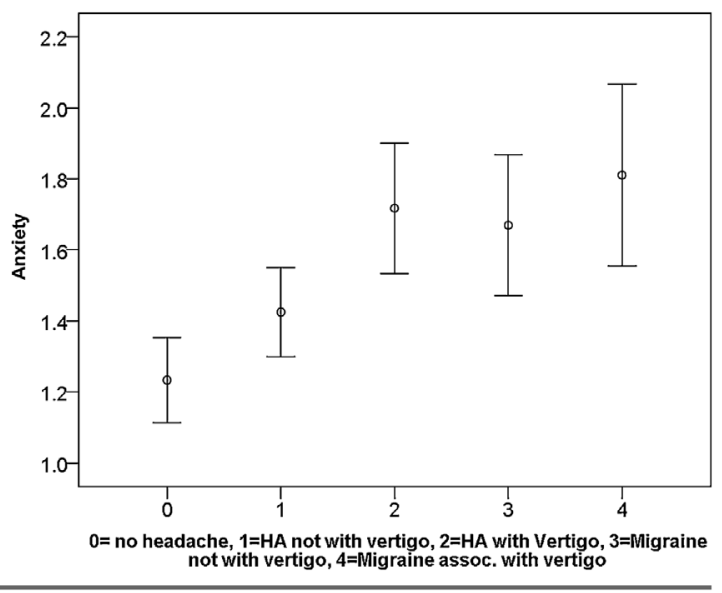

c

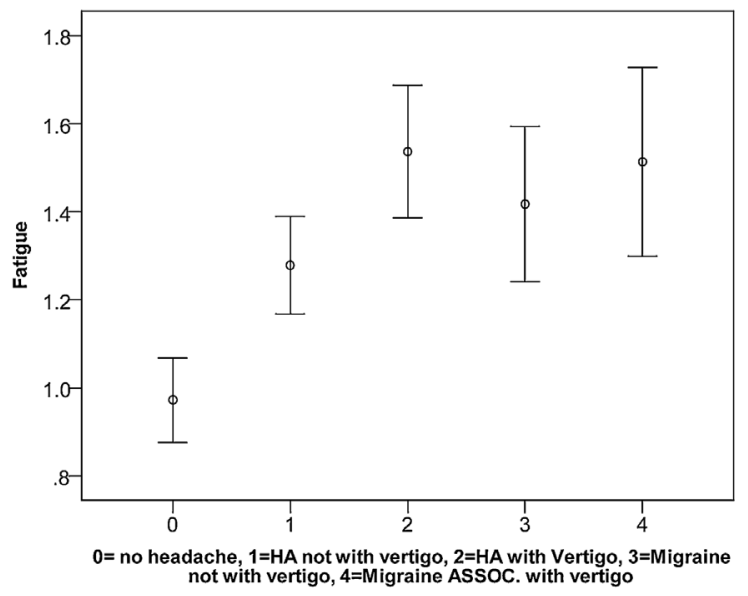

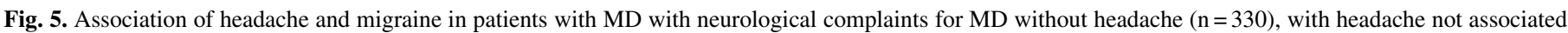

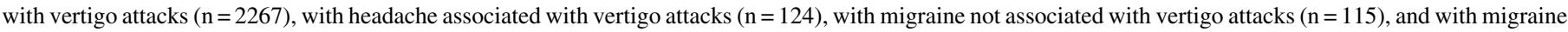

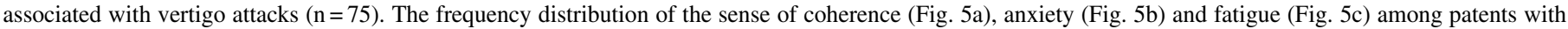

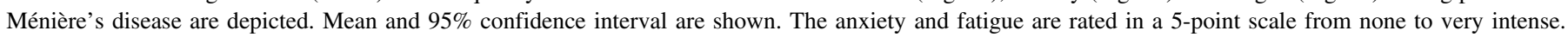

square $=7.237, p=0.05)$. However, the classification tree could predict only $7 \%$ of the patients with MD into the two groups, which highlights the heterogeneity of the disorder.

In logistic regression analysis (See Table 2), we established a model in that three factors could predict VM statistically significantly $(p<0.001)$. However, the model could only predict $4.7 \%$ of the subject in correct class, which further highlights the heterogeneity of the condition. The variables found to be significant predictors in the model were duration of vertigo attack (odds ratio 1.4), environmental pressure change (odds ratio 1.6), and attack-wise tingling or paresthesia of the face (odds ratio 3.8).

\section{Discussion}

The aim of the present study was to evaluate possible differences in complaint characteristics of VM in patients with $\mathrm{MD}$ as the evidence of previous studies indicates that VM often overlaps with symptoms of MD [7,8,44,45]. We could confirm that $\mathrm{MD}$ is frequently associated with headache. The difference

Table 2

Logistic regression to predict the Vestibular Migraine based on symptoms.

\begin{tabular}{|c|c|c|c|c|c|c|c|c|}
\hline \multicolumn{9}{|l|}{ Variables in the equation } \\
\hline & \multirow[t]{2}{*}{ B } & \multirow[t]{2}{*}{ S.E. } & \multirow[t]{2}{*}{ Wald } & \multirow[t]{2}{*}{ df } & \multirow[t]{2}{*}{ Sig. } & \multirow[t]{2}{*}{ Exp. (B) } & \multicolumn{2}{|c|}{ 95\% C.I.for $\operatorname{EXP}(B)$} \\
\hline & & & & & & & Lower & Upper \\
\hline Environmental pressure change & .48 & .136 & 12.44 & 1 & $<.0001$ & 1.617 & 1.238 & 2.112 \\
\hline Tingling in face or disturbance of sensitivity & 1.34 & .312 & 18.54 & 1 & $<.0001$ & 3.836 & 2.080 & 7.072 \\
\hline Constant & -4.44 & .471 & 88.89 & 1 & $<.0001$ & .012 & & \\
\hline
\end{tabular}


between previous studies and the present study was that the presented diagnosis of VM was applied according to recent Bárány Society criteria on the temporal association of migraine with vertigo spells. We found that patients classified as VM in our study group (i.e., those with vertigo spells associated with migraine) often reported complaints of severe MD symptoms, had a reduced health-related quality of life, suffered more from anxiety, had more neurological complaints, and had a reduced sense of coherence. However, the models used to separate MD from VM were without practical values as being able to only explain $7 \%$ and $5 \%$ of the variance in decision tree and logistic regression analyses, respectively. Furthermore, the results indicate that migraine increases the severity of MD. In this line our results support those as reviewed by Tabet and Saliba [17] and by Phillips et al. [14].

The diagnostic criteria for VM were the product of an accord between the classification committees of the IHS and the Bárány Society for classification of VM [46] that would match with the MD classification of the Bárány Society Committee [6]. Nevertheless, there is still a concern in the scientific community about the relevance of VM classification as an independent disorder [14]. So far there is a limited number of studies in which the classification between MD and VM are based on statistical work up [17]. Most studies either describe the association of migraine with vertigo, or of vertigo with migraine. Neff et al. [21] studied 147 patients with VM, MD and Ménière's disease plus Vestibular Migraine (MDVM). The lattermost group amounted to about $25 \%$ of their sample, and the authors concluded that more specific diagnostic criteria was needed to differentiate between these diseases and address their coexistence. We could confirm that migraine $(21 \%)$ and headache $(43 \%)$ are common in patients with MD in line with others $[7,8,47]$. Hence, we support the suggestion by Dolowitz [48] and Neff et al. [21] that headache could be added to the MD as a supplementary complaint; in addition, comorbidity was common between MD and VM, and that their symptoms overlap. We propose that MD with migraine and VM are not synonymous, although individual patients may meet the diagnostic criteria for both conditions. In other words, simultaneous presentation of definite VM and definite MD making this an overlapping syndrome of two diseases has been reported [49]. Such patients can be classified as "VM/MD overlapping syndrome (VM/MD-OS)" as proposed by Murofushi et al. [49]

Anxiety is reported to be a common occurrence with VM. The conjunction of migraine, vestibular symptoms, and anxiety has been termed Migraine-Anxiety-Related Dizziness (MARD) [44]. Phillips et al. [14] also indicated that both migraine and vertigo share a common association with anxiety. Anxiety has also been co-associated with peripheral vestibular disorders such as MD [29,50]. The association between anxiety and sense of coherence was strong, indicating that personality trait is a strong predictor of anxiety as also indicated in MARD [42]. In MD, mobility related symptoms and mood disorders in a broad sense were the most significant determinants of vitality and anxiety [50]. In the present study, we could confirm that anxiety was increased among MD patients who had migraine with frequent vertigo attacks. The same was true also for sense of coherence. In the study by Mendel et al. [51] on vertiginous patients, a low sense of coherence did not correlate with vertigo, but rather with the psychosocial stress and emotional distress caused by the disease. In another study on MD, the sense of coherence appears to reflect the patient's attitude towards illness and correlates with perceived good health [43]. Patients with higher sense of coherence scores were more content with their quality of life and this may partly explain why MD patients with migraine experience the symptoms as more severe.

In $\mathrm{MD}$, the endolymphatic hydrops signifies the disorder as it is present in all patients with definite MD [1]. Light microscopy showed no structural alteration in cochlear sensory hair cells and innervation patterns that could account for the symptoms of MD [52]. A detailed ultrastructural study of a temporal bone using serial electron microscopy in a patient with documented unilateral MD showed a considerable decrease in afferent synapses at the base of both the inner and the outer hair cells in the ear with MD as compared to the contralateral ear [4]. These findings may indicate that the reason for MD can be neuronal in origin. Headache occurred more frequently among patients with MD than in vestibular neuritis [47] and was related to vertigo only in patients with MD, which was suggested to be caused by endolymphatic hydrops, causing headache with trigeminal nerve activation, subsequently leading to loss of sensory neurons in the cochlea [53].

It is important to note that tension type headache among others is very often associated with vertigo (See Headache Classification Committee of the International Headache Society [54]). Also, when reviewing studies of vertigo and migraine, the most commonly associated migraine subtype was migraine without aura $(80 \%)$, and only $12 \%$ had migraine with aura associated to vertigo [55]. Also, the duration of vertigo was less than $5 \mathrm{~min}$ (which is the shortest duration of migraine aura) in $25 \%$ of patients. Among the patients with short-lasting attacks, $75 \%$ of patients had $>5$ attacks/day, which is most probably related to neck muscle proprioceptive problems caused by muscle tension. In another recent study, $25 \%$ of vertigo attacks lasted less than $5 \mathrm{~min}$ and only $20 \%$ of vertigo attacks lasted from $5 \mathrm{~min}$ to $1 \mathrm{~h}$, which is the duration of migraine with aura [56]. These cases might represent the basilar type migraine aura, and support the idea that a portion of vertigo is associated pathophysiologically to migraine.

\subsection{Study limitations}

The current study presents results of a population study among MD to better understand the association between MD and VM. However, the study has a few limitations. First, the VM diagnosis relies on anamnestic self-reported data focusing on migraine and vestibular symptoms. Those with headache attacks associated with vertigo spells may represent probable VM cases. Second, the diagnosis of migraine depended on earlier diagnosis made by physicians, and probably also a significant part of those who had headache might actually have migraine. In a general population sample, $60 \%$ of migraine sufferers were not aware that they had migraine [57], and in one study only a fraction of migraine sufferers were diagnosed [58]. A specific questionnaire might be used to clarify this question, 
but final confirmation demands a medical evaluation. For example, Samaan et al. [59] indicated that with a questionnaire, the sensitivity of migraine is high (87\%) but the specificity is only modest (58\%) when compared with a specialist's diagnosis. On the contrary, by using a 36-page questionnaire, Kallela et al. [60] demonstrated specificity of $99 \%$ and sensitivity of $96 \%$ when compared with a telephone interview of a specialist. Third, the diagnostic criteria for VM proposed by the Bárány Society and the IHS [9] is different from ours as we did not count the number of vertigo attacks in MD in numbers but rather in the frequency of occurrence. This, in our opinion, provides better perspectives of life long history. For these reasons, study results should be interpreted with caution. Future studies should try to use questionnaire-based diagnosis of migraine and repeat the study to also include those patients classified as experiencing headache in more specific headache classes [54].

\section{Conclusions}

In the current literature, there is a significant lack of understanding regarding symptom-based differentiation between MD and VM, and admittedly, diagnosis of VM remains a challenge for neurologists and ENT specialists. Migraine and headache were reported by 190 subjects $(20.9 \%)$ and 391 subjects $(42.9 \%)$ respectively in the current study. We found that patients that could be classified as VM in the study (i.e., those with frequent vertigo spells associated with migraine) voiced more complaints of severe MD symptoms, experienced a reduced health-related quality of life, suffered more from anxiety, had more neurological complaints, and had a reduced sense of coherence. Our study results confirm that MD is frequently associated with headache. In addition, results also indicate that migraine provokes the severity of MD. However, we could not discern any complaints discriminating between VM and MD that would allow reclassification of a patient to MD or VM.

\section{Ethical statement}

Permission was obtained from the Finnish Ménière Federation (FMF; Suomen Meniere-liitto) to allow access to the FMF registry data anonymously (i.e., without the personally identifiable information of subjects). The registry data contained detailed data on disease that the FMF had collected from their members when establishing the computer based diagnostic and peer support program during the years 2005-2016. Under Finnish law, this kind of study conducted in association with patient association does not require ethical approval.

\section{Conflict of interest}

None to declare.

\section{Appendix 1 Supplementary data}

Supplementary material related to this article can be found, in the online version, at doi:https://doi.org/10.1016/j.anl.2019.02.002.

\section{References}

[1] Nakashima T, Pyykkö I, Arroll MA, Casselbrant M, Foster C, Manzoor N, et al. Meniere's disease. Nat Rev Dis Primers 2016;2:16028. http:// dx.doi.org/10.1038/nrdp.2016.28.

[2] Havia M, Kentala E, Pyykkö I. Prevalence of Meniere's disease in general population of Southern Finland. Otolaryngol Head Neck Surg 2005;133(5):762-8.

[3] Yamakawa K. Überdiepatologische veränderungenbeieinem MenièreKranken. J Otol Rhino Laryngol Soc Jpn 1938;44:2310-2.

[4] Nadol JB, Thornton AR. Ultrastructural findings in a case of Menière's disease. Ann Otol Rhinol Laryngol 1987;96:449-54.

[5] AAO-HNS. Committee on Hearing and Equilibrium. Committee on Hearing and Equilibrium guidelines for the diagnosis and evaluation of therapy in Meniere's disease. Oto Laryngol Head Neck Surg 1995;113:181-5.

[6] Lopez-Escameza JA, Carey J, Chungc W-H, Goebeld JA, Magnusson $\mathrm{M}$, Mandalàf $\mathrm{M}$, et al. Diagnostic criteria for Menière's disease. J Vestib Res 2015;25(1):1-7. http://dx.doi.org/10.3233/VES-150549.

[7] Radtke A, Lempert T, Gresty MA, Brookes GB, Bronstein AM, Neuhauser H. Migraine and Meniere's disease: is there a link? Neurology 2002;59(11):1700-4

[8] Rassekh CH, Harker LA. The prevalence of migraine in Menière's disease. Laryngoscope 1992;102:135-8.

[9] Lempert T, Olesen J, Furman J, Waterston J, Seemungal B, Carey J, et al. Vestibular migraine: diagnostic criteria. J Vestib Res 2012;22 (4):167-72. http://dx.doi.org/10.3233/VES-2012-0453.

[10] Moskowitz MA. Basic mechanisms in vascular headache. NeurolClin 1990;20:801-13

[11] Edvinsson L. On migraine pathophysiology. In: Edvinsson L, editor. Migraine and headache pathophysiology. London: Martin Dunez LTD; 1999. p. 3-16.

[12] Espinosa-Sanchez JM, Lopez-Escamez JA. New insights into pathophysiology of vestibular migraine. Front Neurol 2015;6:12. http://dx. doi.org/10.3389/fneur.2015.00012.

[13] Anttila V, Wessman M, Kallela M, Palotie A. Genetics of migraine. Handb Clin Neurol 2018;148:493-503. http://dx.doi.org/10.1016/ B978-0-444-64076-5.00031-4.

[14] Phillips J, Longridge N, Mallinson A, Robinson G. Migraine and vertigo: a marriage of convenience? Headache 2010;50:1362-5.

[15] Frejo L, Soto-Varela A, Santos-Perez S, Aran I, Batuecas-Caletrio A, Perez-Guillen V, et al. Clinical subgroups in bilateral meniere disease. Front Neurol 2016;7:182

[16] Frejo L, Giegling I, Teggi R, Lopez-Escamez JA, Rujescu D. Genetics of vestibular disorders: pathophysiological insights. J Neurol 2016;263 (S1):S45-53. http://dx.doi.org/10.1007/s00415-015-7988-9.

[17] Tabet P, Saliba I. Meniere's disease and vestibular migraine: updates and review of the literature. J Clin Med Res 2017;9(9):733-44. http:// dx.doi.org/10.14740/jocmr3126w.

[18] Kayan A, Hood JD. Neuro-otological manifestations of migraine. Brain 1984;107:1123-42

[19] Dieterich M, Brandt T. Episodic vertigo related to migraine (90 cases): vestibular migraine? J Neurol 1999;246(10):883-92.

[20] Moretti G, Manzoni GC, CaffarraP Parma M. "Benign recurrent vertigo" and its connection with migraine. Headache 1980;20:344-6.

[21] Neff BA, Staab JP, Eggers SD, Carlson ML, Schmitt WR, Van Abel $\mathrm{KM}$, et al. Auditory and vestibular symptoms and chronic subjective dizziness in patients with Meniere's disease, vestibular migraine, and Meniere's disease with concomitant vestibular migraine. Otol Neurotol 2012;33(7):1235-44

[22] Brantberg K, Baloh RW. Similarity of vertigo attacks due to Meniere's disease and benign recurrent vertigo, both with and without migraine. Acta Oto laryngol 2011;131(7):722-7.

[23] Nakada T, Yoshida T, Suga K, Kato M, Otake H, Kato K, et al. Endolymphatic space size in patients with vestibular migraine and Meniere's disease. J Neurol 2014;261:2079-84.

[24] Gürkov R, Strobl R, Heinlin N, Krause E, Olzowy B, Koppe C, et al. Atmospheric pressure and onset of episodes of menière's disease - a repeated measures study. PLoS One 2016;11(4):e0152714. http://dx. doi.org/10.1371/journal.pone.0152714. eCollection 2016. 
[25] Kirsch V, Becker-Bense S, Berman A, Kierig E, Ertl-Wagner B, Dieterich M. Transient endolymphatic hydrops after an attack of vestibular migraine: a longitudinal single case study. J Neurol 2018;265(Suppl. 1):51-3. http://dx.doi.org/10.1007/s00415-0188870-3. Epub 2018 April 25.

[26] AAO-HNS. Committee on Hearing and Equilibrium. Report of subcommittee on equilibrium and its measurement. Meniere's disease: criteria for diagnosis and evaluation of therapy for reporting. Trans Am Acad Ophthalmol Otolaryngol 1972;76:1462-4.

[27] Neuhauser H, Leopold M, von Brevern M, Arnold G, Lempert T. The interrelations of migraine, vertigo, and migrainous vertigo. Neurol 2001;56:436-41.

[28] Pyykkő I, Nakashima T, Yoshida T, Zou J, Naganawa S. Meniere's disease: a reappraisal supported by a variable latency of symptoms and the MRI visualisation of endolymphatic hydrops. BMJ Open 2013;3(2):e1555. http://dx.doi.org/10.1136/ bmjopen-2012- 001555.

[29] Pyykkő I, Manchaiah V, Levo H, Kentala E. Impact evaluation and association with EuroQol 5D health-related utility values in Ménière's disease. Springer Plus 2015;4:717. http://dx.doi.org/10.1186/s40064-015-1527-0.

[30] Stephens D, Pyykkő I, Varpa K, Kentala E. Self-reported effects of Menière's Disorder on the individual's life: a qualitative analysis. Otol Neurotol 2010;31(2):335-8.

[31] Levo H, Stephens D, Kentala E, Poe D, Pyykkö I. Euro Qol 5D quality of life in Menière's disorder can be explained with symptoms and disabilities. Int J Rehabil Res 2012;35(3):197-202.

[32] Rasku J, Pyykkö I, Levo H, Kentala E, Manchaiah V. Disease profiling for computerized peer support of Ménière's disease. JMIR Rehabil Assist Technol 2015;2(2):e9. http://dx.doi.org/10.2196/rehab.4109.

[33] Pyykkő I, Manchaiah V, Levo H, Kentala E, Juhola M. Internet-based peer support for Ménière's disease: a summary of web-based data collection, impact evaluation, and user evaluation. Int J Audiol 2017;56 (7):453-63. http://dx.doi.org/10.1080/14992027.2017.1282631.

[34] Pyykkő I, Manchaiah V, Levo H, Kentala E, Juhola M. Internet-based self-help for Ménière's disease: details and outcome of a single-group open trial. Am J Audiol 2017;26(4):496-506. http://dx.doi.org/ 10.1044/2017_AJA-16-0068.

[35] Manchaiah V, Pyykkö I, Zou J, Levo H, Kentala E, Juhola M. Patientreported benefits from patient organization magazines and Internetbased peer support in Ménière's disease. Patient Prefer Adherence 2017;11:1851-7. http://dx.doi.org/10.2147/PPA.S142257.

[36] Auramo Y, Juhola M, Pyykkö I. An expert system for the computer-aided diagnosis of Dizziness and vertigo. Med Inform 1993;18(4):293-305.

[37] Kentala E, Pyykkö I, Auramo Y, Juhola M. Database for vertigo. Otolaryngol Head Neck Surg 1995;112(3):383-90.

[38] Kentala E. Characteristics of six otologic diseases involving vertigo. Am J Otol 1996;17(6):883-92.

[39] Rabin R, de Charro F. EQ-5D: a measure of health status from the EuroQol Group. Ann Med 2001;33(5):337-43.

[40] Antonovsky A. The structure and properties of the sense of coherence scale. Soc Sci Med 1993;36(6):725-33.

[41] Sintonen H. The 15D instrument of health-related quality of life: properties and applications. Ann Med 2001;33(5):328-36.

[42] Stanton A, Revenson T, Tennen H. Health psychology: psychological adjustment to chronic disease. Annu Rev Psychol 2007;58:565-92.
[43] Ketola S, Kentala E, Stephens D, Varpa K, Pyykkö I. The sense of coherence in patients with Menière's disorder. Auris Nasus Larynx 2014;41(3):244-8. http://dx.doi.org/10.1016/j.anl.2013.12.008.

[44] Furman JM, Balaban CD, Jacob RG, Marcuset DA. Migraine-anxiety related dizziness (MARD): a new disorder? J Neurol Neurosurg Psychiatry 2005;76(1):1-8

[45] Cha YH, Brodsky J, Ishiyama G, Sabatti C, Baloh RW. The relevance of migraine in patients with Meniere's disease. Acta Otolaryngol 2007;127(12):1241-5.

[46] Bisdorff A, von Brevern M, Lempert T, Newman-Toker DE. Classification of vestibular symptoms: towards an international classification of vestibular disorders. J Vestib Res 2009;19(1-2):1-13. http://dx.doi. org/10.3233/VES-2009-0343.

[47] Eklund S. Headache in Meniere's disease. Auris Nasus Larynx 1999;26 (4): $427-33$

[48] Dolowitz D. Meniere's disease — an inner ear seizure. Laryngoscope 1979;89:67-77.

[49] Murofushi T, Tsubota M, Kitao K, Yoshimura E. Simultaneous presentation of definite Vestibular Migraine and definite Ménière's Disease: overlapping syndrome of two diseases. Front Neurol 2018;9:749. http://dx.doi.org/10.3389/fneur.2018.00749.

[50] Levo H, Stephens D, Poe D, Kentala E, Pyykkő I. Fatigue in Meniere's disease. Hearing Balance Commun 2013;11(4):191-7.

[51] Mendel B, Bergius J, Langius A. The Sense of Coherence: a tool for evaluating patients with peripheral vestibular disorder. Clin Otolaryngol Allied Sci 2001;26(1):19-24.

[52] Schuknecht HF, Gacek MR. Cochlear pathology in presbycusis. Ann Otol Rhinol Laryngol 1993;102(1 Pt 2):1-16.

[53] Vass Z. Endolymphatic hydrops reduces retrograde labeling of trigeminal innervation to the cochlea. Exp Neurol Suppl 1998;151(2):241-8.

[54] Headache Classification Committee of the International Headache Society. (IHS) the international classification of headache disorders, 3rd edition. Cephalalgia 2018;38(1):1-211. http://dx.doi.org/10.1177/ 0333102417738202.

[55] Zhang L-M, Dong Z, Yu S-Y. Migraine in the era of precision medicine. Ann Transl Med 2016;4(6):105. http://dx.doi.org/10.21037/ atm.2016.03.13

[56] Teggi R, Manfrin M, Balzanelli C, Gatti O, Mura F, Quaglieri S, et al. Point prevalence of vertigo and dizziness in a sample of 2672 subjects and correlation with headaches. Acta Otorhinolaryngol Ital 2016;36 (3):215-9. http://dx.doi.org/10.14639/0392-100X-847.

[57] Lucas C, Geraud G, Valade D, Chautard M-H, Lanteri-Minet M. Recognition and therapeutic management of migraine in 2004, in France: results of FRAMIG 3, a French Nationwide Population-Based Survey. Headache 2006;46(5):715-25. 3.

[58] Lipton RB, Stewart WF, Celentano DD. Reed ML: undiagnosed migraine headaches. A comparison of symptom-based and reported physician diagnosis. Arch Intern Med 1992;152(6):1273-8.

[59] Samaan Z, MacGregor EA, Dowson A, McGuffin P, Farmer A. Diagnosing migraine in research and clinical settings: the validation of the structured Migraine Interview (SMI). BMC Neurol 2010;10:7. http://dx.doi.org/10.1186/1471-2377-10-7.

[60] Kallela M, Wessman M, Färkkilä M. Validation of a migraine-specific questionnaire for use in family studies. Eur J Neurol 2001;8(1):61-6. 